\title{
DESIGN AND STUDY OF THE EFFECT OF MULTIPLE MACHINING PARAMETERS IN TURNING OF AL6063T6 USING TAGUCHI METHOD
}

\author{
Chandra Shekar \\ Research Scholar, Mechanical Engineering, JAIN University, Bangalore, Karnataka, India
}

N B D Pattar

Professor \& Principal, Sri Revana Siddeshwara Institute of Technology, Bangalore, Karnataka, India

\section{Y Vijaya Kumar}

Professor \& Principal, Sri Sairam College of Engineering, Anekal, Bangalore, Karnataka, India

\begin{abstract}
An attempt has been made into the role of conducting an experimental research on aluminium alloys by using the technique to find and correlate Taguchi technological factors for the economy of the machining process. The powerful statistical tool Taguchi method is a systematic application of design and analysis of experiments. It is an effective way to produce high quality at a relatively low cost method. Improving one parameter leads to degradation of other parameters and optimization of various parameters is much more complicated. Therefore, Taguchi technique is used to investigate the characteristic multiple performance in turning operation. In this paper, the effect of the variation of machining parameters such as speed, power, depth of cut and radius nose in Al6063T6 has been studied and presented. First, the optimal arrangement of the four parameters of rotation has been determined using the configuration of the Taguchi L9 technique with a variation in three levels. After machining is completed, the values are documented and compared using statistical analysis software.
\end{abstract}

Key words: Machinability; Taguchi technique; cutting parameters; machining environment; interaction effect

Cite this Article: Chandra Shekar, N B D Pattar and Y Vijaya Kumar, Design and Study of the Effect of Multiple Machining Parameters in Turning of AL6063T6 Using Taguchi Method. International Journal of Design and Manufacturing Technology 7(3), 2016, pp. 12-18. https://iaeme.com/Home/issue/IJDMT?Volume=7\&Issue=3

\section{INTRODUCTION}

Machining is a term that covers a large collection of manufacturing processes designed to remove unwanted material, usually in the form of chips, from a work-piece. Machining is used to convert castings, forgings, or preformed blocks of metal into desired shapes, with size and finish specified to fulfil design requirements. Almost every manufactured product has components that require machining, often to great 
precision. The majority of industrial applications of machining are in metals. Although the metal cutting process has resisted theoretical analysis because of its complexity, the application of these processes in the industrial world is widespread. Metal cutting processes can be viewed as consisting of independent input variables, dependent variables, and independent-dependent interactions or relationships. The engineer or machine tool operator has direct control over the input variables and can specify or select them when setting up the machining process.

The three most common cutting tool materials currently in use for production machining operations are High-Speed Steel, both in wrought and powder metallurgy form, carbides and coated tools. Cubic Boron Nitride, ceramics, and diamonds are also being widely employed. Selection of a tool material that provides reliable service while fulfilling the functional requirements is still an art. The harder the tool material, the better it can resist wear at faster cutting speeds. The faster the cutting speed, higher the cutting temperature and the shorter the tool life. Retention of hardness at elevated temperatures as well as long tool life is desirable characteristics in cutting tools.

For every machining operation, it is necessary to select a cutting speed, a feed, and a depth of cut. Many factors impinge on these decisions because all of the dependent variables are influenced by them. Proper selection of variables also depends on the other input variables that have been selected, that is, the total amount of material to be removed, the work piece and tool materials, and the machining process or processes. These need to be selected before preliminary choices for speed, feed, and depth of cut can be made.

Cutting tools are usually designed to accomplish specific operations, and thus the tool geometry is selected to accomplish specific machining functions. Generally speaking, large rake and clearance angles are preferred, but they are possible only on High Speed Steel tools. Tools made from carbides, ceramics, and other very hard materials must be given small tool angles, which keep the tool material in compression during machining and thereby avoid tensile failure and brittle fractures of the tool. The greater the precision required of the process, the better the geometry of the cutting edge itself must be.

The selection of the right cutting fluid for a particular combination of work material and tool material can mean the difference between success and failure in almost every production machining process. Cutting fluids serve to cool the work piece, tool, and chips, to reduce friction by means of lubrication, to carry the chips away from the cutting region, to help improve the surface finish and to provide surface protection to the work piece.

\section{OBJECTIVES OF THE WORK}

The objective of the work is to discuss the interaction effect of the cutting parameters on the machining of aluminium alloy in order to find the following parameters by both experimentally and Taguchi techniques.

- To develop relationship between the control parameters and response parameters during machining.

- To optimize turning operation parameters for surface roughness, material removal, machining force and power consumption.

- To optimize unit production cost and it is established on the basis of actual machining time, setup time, tool re-use time, tool life and tool changing time.

\section{EXPERIMENTAL STUDY}

The as-received Al6063T6 alloys were used in this study and its chemical composition is given in the Table 1. Al6063T6 alloy is the least expensive and most versatile of the heat treatable among the aluminium alloys. It offers a range of good mechanical properties and also good corrosion resistance. Its strength to weight ratio is excellent and it is ideally used for highly stressed parts. It may be formed in the annealed condition and subsequently heat treated. 
Table 1 Chemical Composition Al6063t6 Aluminum Alloys in Weight Percentage

\begin{tabular}{|c|c|c|c|c|c|c|c|c|c|c|}
\hline Alloy & $\mathbf{S i}$ & $\mathbf{F e}$ & $\mathbf{C u}$ & $\mathbf{M n}$ & $\mathbf{T i}$ & $\mathbf{M g}$ & $\mathbf{C r}$ & $\mathbf{Z n}$ & Others & Al \\
\hline Al6063T6 & $\begin{array}{c}0.2- \\
0.6\end{array}$ & $\begin{array}{c}0- \\
0.35\end{array}$ & $0-0.1$ & $0-0.1$ & $0-0.1$ & $0.45-0.9$ & $0-0.1$ & $0-0.1$ & $0-0.05$ & Bal \\
\hline
\end{tabular}

Experimental design for an L9 orthogonal array was done using Taguchi method. Hence, it has been possible to reach more comprehensive results with doing fewer experiments. In this sense, time and money have been used more efficiently [7-8]. In the determination of the characteristics of the quality as the rates of surface roughness to be measured, MRR, cutting time, and cutting force were required to be minimum, "less is more" principle has been applied among the quality values expected to be reached at the end of the experiments.

The control parameters were cutting speed (V), feed rate (f). Three levels were specified for each of the factors as indicated in Table 2. The orthogonal array chosen was L9, which has 9 rows corresponding to the number of parameter combinations ( 8 degrees of freedom). The first column was assigned to the cutting speed $(\mathrm{V})$, the second column to the feed rate (f).

Table 2 Assignment of the Levels to the Factors

\begin{tabular}{|c|c|c|c|c|c|}
\hline \multirow{2}{*}{ CUTTING PARAMETERS } & \multirow{2}{*}{ UNIT } & \multirow{2}{*}{ NOTATION } & \multicolumn{3}{|c|}{ LIMITS } \\
\cline { 4 - 6 } & & & Level 1 & Level 2 & Level 3 \\
\hline Feed rate & $\mathrm{mm} / \mathrm{min}$ & $\mathrm{f}$ & 10 & 40 & 70 \\
\hline Cutting speed & $\mathrm{rpm}$ & $\mathrm{V}$ & 500 & 1000 & 1500 \\
\hline Depth of cut & $\mathrm{mm}$ & $\mathrm{d}$ & 0.3 & 0.5 & 0.8 \\
\hline Tool nose radius & $\mathrm{mm}$ & $\mathrm{r}$ & 0.4 & 0.6 & 0.8 \\
\hline
\end{tabular}

Table 3 Physical Layout for L9

\begin{tabular}{|c|c|c|c|c|}
\hline Expt. No. & $\begin{array}{c}\text { Nose radius } \\
(\mathbf{m m})\end{array}$ & $\begin{array}{c}\text { Feed } \\
(\mathbf{m m} / \mathbf{m i n})\end{array}$ & $\begin{array}{c}\text { Speed } \\
(\mathbf{R P M})\end{array}$ & $\begin{array}{c}\text { DOC } \\
(\mathbf{m m})\end{array}$ \\
\hline 1 & 0.400 & 10.000 & 500 & 0.300 \\
\hline 2 & 0.400 & 40.000 & 1000 & 0.500 \\
\hline 3 & 0.400 & 70.000 & 1500 & 0.800 \\
\hline 4 & 0.600 & 10.000 & 1000 & 0.800 \\
\hline 5 & 0.600 & 40.000 & 1500 & 0.300 \\
\hline 6 & 0.600 & 70.000 & 500 & 0.500 \\
\hline 7 & 0.800 & 10.000 & 1500 & 0.500 \\
\hline 8 & 0.800 & 40.000 & 500 & 0.800 \\
\hline 9 & 0.800 & 70.000 & 1000 & 0.300 \\
\hline
\end{tabular}




\subsection{Taguchi Analysis for AL6063T6 Alloy}

The experimental results of the machining characteristics obtained for the turning parameters mentioned in table 3 are given in table 4.

Table 4 Experimental Results For AL6063T6 Alloy

\begin{tabular}{|c|c|c|c|c|c|}
\hline $\begin{array}{c}\text { Expt. } \\
\text { No. }\end{array}$ & $\begin{array}{c}\text { Surface Roughness } \\
(\mathbf{R a}) \\
(\boldsymbol{\mu m})\end{array}$ & $\begin{array}{c}\text { MRR } \\
(\mathbf{m m} \mathbf{3} / \mathbf{m i n})\end{array}$ & $\begin{array}{c}\text { Machining Time } \\
(\mathbf{m i n})\end{array}$ & $\begin{array}{c}\text { Machining } \\
\text { Force } \\
(\mathbf{N})\end{array}$ & $\begin{array}{c}\text { Power } \\
(\mathbf{W})\end{array}$ \\
\hline 1 & 2.016 & 235.619 & 11.475 & 3.000 & 1.963 \\
\hline 2 & 7.141 & 1570.796 & 1.650 & 10.000 & 13.090 \\
\hline 3 & 7.682 & 4398.230 & 0.632 & 18.667 & 36.652 \\
\hline 4 & 1.764 & 628.319 & 4.480 & 4.000 & 5.236 \\
\hline 5 & 7.024 & 942.478 & 3.222 & 4.000 & 7.854 \\
\hline 6 & 7.213 & 2748.894 & 0.849 & 35.000 & 22.907 \\
\hline 7 & 1.580 & 392.699 & 7.168 & 1.667 & 3.272 \\
\hline 8 & 4.927 & 2513.274 & 1.282 & 32.000 & 20.944 \\
\hline 9 & 7.648 & 1649.336 & 1.415 & 10.500 & 13.744 \\
\hline
\end{tabular}

\section{RESULTS AND DISCUSSION}

The main objective of the experiment is to optimize the turning parameters (cutting speed, feed rate, speed and nose radius) to achieve low value of the cutting parameters. The interaction effect between the factors of the cutting parameters such as FXS, FXD, FXNr, SXD, SXNr, DXNr (where F=feed, S=speed, D=depth of cut and $\mathrm{Nr}=$ Nose radius) on surface roughness is investigated and reported as below.

Figure 5.2 shows the results of interaction between feed, speed, depth of cut, nose radius and surface roughness which are obtained from the experiment.

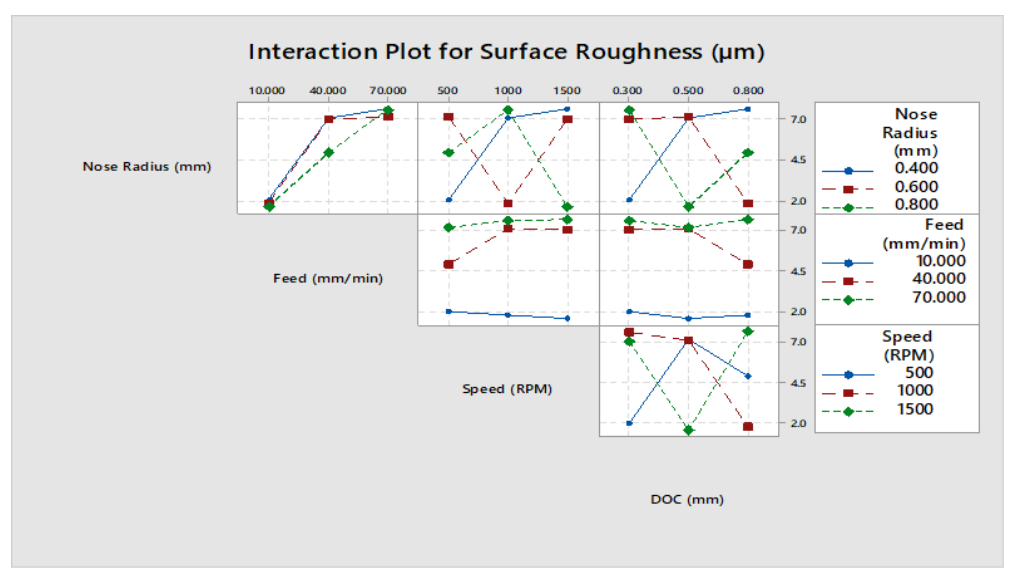

Figure 1 Interaction effects plot for surface roughness vs cutting parameters

Figure 1 gives the interaction plot between the cutting parameters and the surface roughness. The plot gives the interaction between two parameters and surface roughness to indicate the lowest value of surface roughness for the Aluminium alloy Al6063T6. 


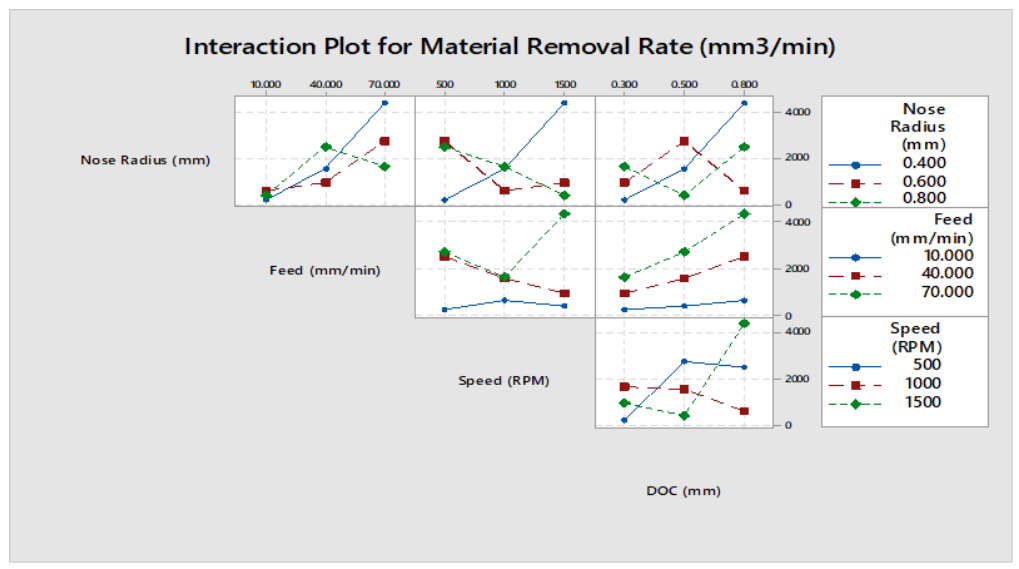

Figure 2 Interaction effects plot for Material Removal Rate vs cutting parameters

Figure 2 gives the interaction plot between the cutting parameters and material removal rate. The plot gives the interaction between two parameters and material removal rate to indicate the highest value of material removal rate for the Aluminium alloy Al6063T6.

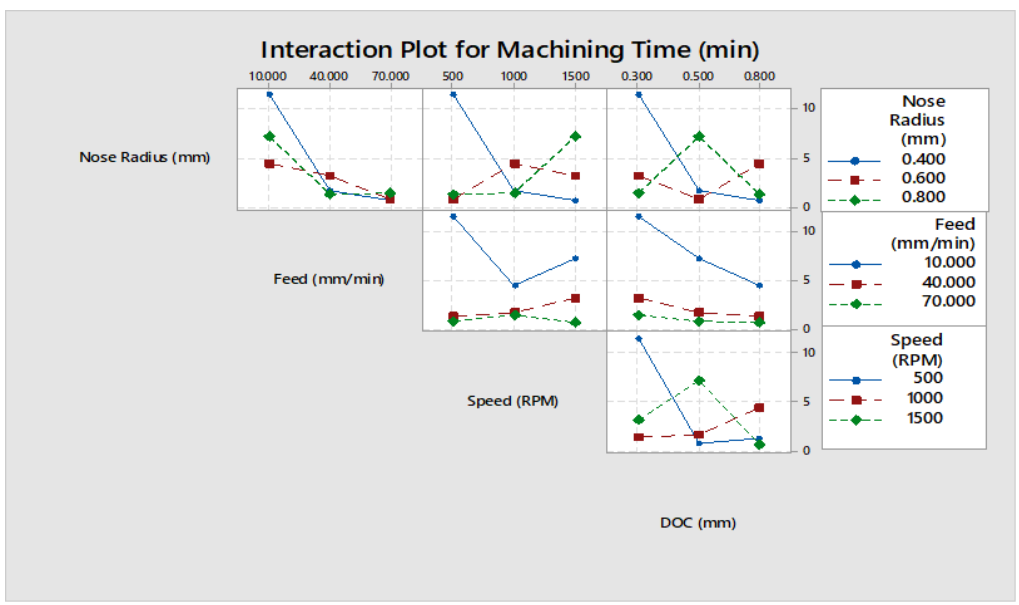

Figure 3 Interaction effects plot for Machining Time vs cutting parameters

Figure 3 gives the interaction plot between the cutting parameters and machining time. The plot gives the interaction between two parameters and machining time to indicate the highest value of machining time for the Aluminium alloy Al6063T6.

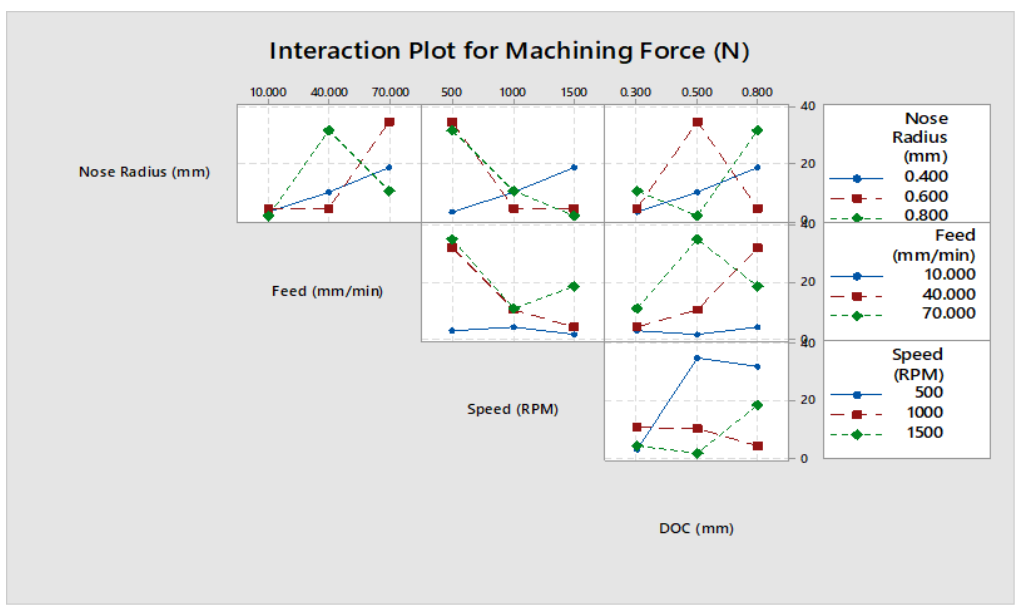

Figure 4 Interaction effects plot for Machining Force vs cutting parameters 
Figure 4 gives the interaction plot between the cutting parameters and machining force. The plot gives the interaction between two parameters and machining force to indicate the highest value of machining force for the Aluminium alloy Al6063T6.

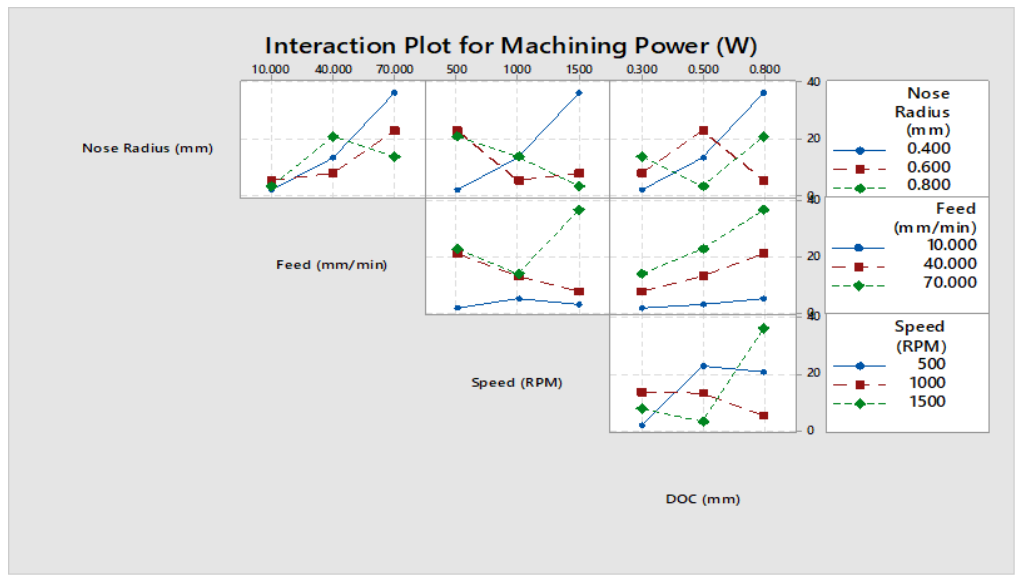

Figure 5 Interaction effects plot for Machining Power vs cutting parameters

Figure 5 gives the interaction plot between the cutting parameters and machining power. The plot gives the interaction between two parameters and machining power to indicate the highest value of machining power for the Aluminium alloy A16063T6.

\section{CONCLUSION}

An experimental design was carried out using Taguchi technique to reduce the number of experiments done for 4 factors and 3 levels. The experiment was conducted to optimize the cutting parameters for turning of aluminium alloy Al6063T6 on a CNC machine. The Taguchi analysis for interaction of the parameters (ie., Surface roughness, Material removal rate, machining time, machining force and machining power) was done to determine the optimum machining parameter setting. From the interaction effects plot obtained from statistical analysis software, we can conclude that the interaction between speed and DOC has the highest effect on all the response parameters followed by the interaction between feed and speed. Other parameters show very little significance and have a lower impact on the response parameters.

\section{REFERENCES}

[1] Lalwani, D.I., Mehta, N.K., \& Jain, P.K. (2008), "Experimental investigations of cutting parameters influence on cutting forces and surface roughness in finish hard turning of MDN250 steel", Journal of Materials Processing Technology, vol. 206, pp. 167-179.

[2] El Baradie, M.A., 1997, Surface roughness prediction in the turning of high strength steel by factorial design of experiments. Mater. Process. Technol., vol. 67, p. 55-61.

[3] W.H. Yang and Y.S. Tarng, "Design optimization of cutting parameters for turning operations based on the Taguchi method", Journal of Materials Processing Technology, Volume 84, Issues 1-3, 1998, Pages 122-129, DOI:https://doi.org/10.1016/S0924-0136(98)00079-X

[4] Arbizu, I.P., Perez, C.J.L., 2003, Surface roughness prediction by factorial design of experiments in turning processes. Mater. Process. Technol., vol. 143-144, p. 390-396.

[5] Abouelatta, O.B., Mádl, J., 2001, Surface roughness prediction based on cutting parameters and vibrations in turning operations. Mater. Process. Technol., vol. 118, p. 269-277.

[6] Roy, R.K., 1990, "A Primer on the Taguchi method.” Competitive Manufacturing Series, New York, USA 
[7] C.Y. Nian, W.H. Yang, Y.S. Tarng, 1999, "Optimization of turning operations with multiple performance characteristics”, J. Mater. Process. Technol. 95, 90-96.

[8] W.S. Lin, B.Y. Lee, C.L. Wu, 2001, "Modeling the surface roughness and cutting force for turning", J. Mater. Process. Technol. 108, 286-293.

[9] H. Wang, S. To, C.Y. Chan, C.F. Cheung, W.B. Lee, 2010, “A theoretical and experimental investigation of the tool-tip vibration and its influence upon surface generation in single-point diamond turning”, Int. J. Mach. Tools \& Manuf. 50, 241-252.

[10] Abouelatta, O.B., Mádl, J., 2001, "Surface roughness prediction based on cutting parameters and vibrations in turning operations", Mater. Process. Technol., vol. 118, p. 269-277

[11] W.H. Yang, Y.S. Tarng, 1998, "Design optimization of cutting parameters for turning operations based on Taguchi method”, J. Mater. Process. Technol. 84, 112-129.

[12] M. Marcos-Barcarena, M. Sebastian Perez, J. Contreras-Samper, M. Sanchez-Carrilero, M. SanchezLopez, J. Sanchez-Sola, 2005, "Study of roundness on cylindrical bars turned of aluminium-copper alloys", UNS A92024, J. Mater. Process. Technol. 162-163, 644- 648.

[13] Y. Li, T. Ngai, W. Xia, Y. Long, D. Zhang, 2003, "A study of aluminium bronze adhesion on tools during turning”, J. Mater. Process. Technol. 138, 479-483.

[14] R K Rajput, 2007, “Manufacturing technology”, laxmi publications, New Delhi.

[15] Garimella Sridhar and P. Ramesh Babu, Cutting Parameter Optimization for Minimizing Machining Distortion of Thin Wall Thin Floor Avionic Components Using Taguchi Technique. International Journal of Mechanical Engineering and Technology (IJMET), 4(4), 2013, pp. 71-78.

[16] Kirankumar Ramakant rao Jagtap, S.B.Ubale and Dr.M.S.Kadam, Optimization of Cylindrical Grinding Process Parameters for AISI 5120 Steel Using Taguchi Method. International Journal of Design and Manufacturing Technology (IJDMT) 2(1), 2012, pp. 47-56 